\title{
DISCUSSÃO DO PROJETO PEDAGÓGICO DE UM CURSO AVALIADO NO PROVÃO COM CONCEITO "A" POR CINCO VEZES CONSECUTIVAS
}

\author{
Galdenoro Botura Jr., ${ }^{1}$ Tânia Cristina A. M. de Azevedo, ${ }^{2}$ Marilza Antunes de Lemos, ${ }^{3}$ \\ Márcio Alexandre Marques, ${ }^{4}$ Luiz Carlos Rosa ${ }^{5}$
}

\begin{abstract}
RESUMO
Este trabalho apresenta o processo de elaboração do Projeto Pedagógico desenvolvido e implantado no curso de Engenharia Elétrica da Faculdade de Engenharia do Campus de Guaratinguetá - UNESP, que trouxe como resultado, a classificação com o conceito "A" no antigo Exame Nacional de Curso - Provão do MEC, por cinco vezes consecutivas. No texto, são apresentados o cenário preexistente e que culminou na elaboração desse novo projeto, os pontos que balizaram a sua construção, a estratégia de implantação adotada, as quebras de paradigmas implementadas e os resultados obtidos. Ressaltam-se, também, as razões que o levaram a ser adotado como ponto de partida para a elaboração dos projetos pedagógicos que resultaram na implantação de dois novos cursos: o de Engenharia Elétrica da Universidade Estadual de Londrina - UEL, e o curso de Engenharia de Controle e Automação do Campus Experimental de Sorocaba - UNESP.
\end{abstract}

Palavras-chave: Projeto Pedagógico; reforma curricular; Engenharia Elétrica; Exame Nacional de Curso.

\section{DISCUSSION OF THE PEDAGOGICAL PROJECT OF A COURSE RATED IN THE MEC GENERAL TEST EVALUATION WITH AN "A" FOR FIVE CONSECUTIVE TIMES}

\begin{abstract}
This paper presents the drafting process of a pedagogical project developed and implemented in the Electrical Engineering Course at Faculty of Engineering, Campus Guaratinguetá UNESP. Applying the project in this course resulted in "A" concept classification in the old National Examination Course, known as MEC General Test (Provão), for five consecutive times. The text presents pre-existing scenario which culminated with the preparation of this new project, the points that guided its construction, the deployment strategy adopted, changing paradigms implemented and results obtained. The text also emphasizes the reasons which led it to be adopted as a starting point for the development of educational projects which resulted in the deployment of two new courses: Electrical Engineering from the Universidade Estadual de Londrina - UEL, and Engineering course control and Automation of Experimental Campus Sorocaba - UNESP.
\end{abstract}

Keywords: Pedagogical Project; curricular reform; Electrical Engineering; National Examination Course.

\footnotetext{
Professor Adjunto, livre-docente, Campus Experimental de Sorocaba - UNESP; galdenoro@sorocaba.unesp.br Professora Doutora, Faculdade de Engenharia do Campus de Guaratinguetá - UNESP; tmacedo@feg.unesp.br Professora Doutora, Campus Experimental de Sorocaba - UNESP; marilza@sorocaba.unesp.br Professor Doutor, Campus Experimental de Sorocaba - UNESP; marciomq@sorocaba.unesp.br Professor Doutor, Campus Experimental de Sorocaba - UNESP; luizrosa@sorocaba.unesp.br
} 


\section{INTRODUÇÃO}

Muitas são as razões que levam um curso de Engenharia a ter sucesso e vir a ser avaliado cinco vezes seguidas com o conceito máximo do Exame Nacional de Cursos, o conhecido "Provão". A qualidade do corpo docente, as instalações físicas, a seleção dos alunos, entre outras variáveis, certamente compõem o quadro que determina o sucesso de um curso. Além de todos esses fatores, um dos componentes fundamentais desse sucesso está relacionado ao seu Projeto Pedagógico. Todas as outras variáveis terão sua importância diminuída no resultado final, caso inexista um Projeto Pedagógico arrojado, com novas propostas para problemas antigos, com soluções criativas e proposições de novos paradigmas, e que traga, também, motivação para o corpo docente e discente, despertando em todos a vontade de ensinar e de aprender.

Este artigo apresenta, analisa e discute as principais razões do sucesso da proposta do curso de Engenharia Elétrica da Faculdade de Engenharia de Guaratinguetá - FEG/UNESP, que, a partir do término da implantação de um novo Projeto Pedagógico, em 1999, recebeu o conceito "A" no antigo "Provão", todas as vezes que este foi aplicado. São apresentadas, também, as principais razões de sua utilização como base na elaboração dos projetos pedagógicos que culminaram com a implementação de dois novos cursos de sucesso na área de Engenharia, o curso de Engenharia Elétrica da Universidade Estadual de Londrina - UEL (BOTURA JUNIOR; ZANI; VICENTE, 2000), e o curso de Engenharia de Controle e Automação do Campus de Sorocaba - UNESP (BOTURA JUNIOR et al., 2002).

\section{CENÁRIO PREEXISTENTE}

\section{Engenharia Elétrica da FEG/UNESP}

$\mathrm{O}$ curso de Engenharia Elétrica da FEG/UNESP iniciou as suas atividades em 1987, tendo como proposta original o oferecimento, aos seus alunos, de uma formação que capacitasse à atuação na interface eletrotécnica e eletrônica. Esse perfil foi definido a partir da identificação de que, na época, grande parte dos profissionais atuantes no mercado de trabalho tinha conhecimentos voltados ou para a área de eletrotécnica ou para a área de eletrônica, e que apenas uma pequena parte deles possuía conhecimentos para atuar na interface das duas áreas.

\section{Corpo discente}

Ao campus de Guaratinguetá convergiam, principalmente, alunos provenientes das mais diversas cidades paulistas, do Vale do Paraíba, Litoral Norte e da própria capital do estado de São Paulo, e de estados vizinhos, vindos do sul de Minas Gerais e do estado do Rio de Janeiro. Pelo grande parque industrial instalado no Vale do Paraíba e por haver uma demanda crescente de engenheiros com a qualificação oferecida, a maior parte dos egressos possivelmente acabaria por trabalhar nessa região.

No início do estudo para a elaboração de um novo Projeto Pedagógico, dezembro de 1993, o curso contava com duas turmas graduadas, com um total de 41 engenheiros atuando no mercado.

No curso de Engenharia Elétrica, a FEG/UNESP oferecia, anualmente, quarenta vagas para ingressantes, selecionados por intermédio da Fundação para o Vestibular da UNESP - VUNESP. Uma análise detalhada demonstrou que os ingressantes eram de nível médio (com nota obtida no vestibular em conhecimentos específicos entre 23,5 e 62,5). Muitos desses alunos destacavam-se nos estudos durante o curso, mostrando-se capazes de executar projetos complexos com sucesso, como os propostos em Iniciação Científica. Em contrapartida, outros precisavam da revisão de conteúdos próprios do colegial. O nível dos alunos matriculados pelo processo de transferência era equilibrado, sendo, em alguns casos, excelente e em outros casos insatisfatório.

O quadro demonstrativo das matrículas, evasão e formandos do curso, desde sua 
criação até a elaboração do projeto pedagógico, está apresentado na Tabela I, adiante.

Analisando os dados dessa tabela, verifica-se que o curso possuía evasão média de 21,5\%, ao longo dos seus sete anos de funcionamento. Nas duas turmas que colaram grau, graduaram-se 41 alunos, aproximadamente $50 \%$ do número de ingressantes. Em função do número de matrículas, bem como dos alunos recebidos em transferência, concluiu-se que 179 discentes continuavam matriculados no curso, distribuídos entre suas séries. Observou-se uma retenção excessiva na $3^{\mathrm{a}}$ série do curso. Esse fato pode ser relacionado com a necessidade de o aluno cursar um número maior de disciplinas profissionalizantes simultaneamente, o que exigia um número maior de horas extraclasse dedicadas aos estudos, projetos e atividades práticas. Em função disso, havia a necessidade de uma melhor organização do tempo de estudo, que nem sempre era atendida pelo aluno, trazendo como consequência a sua reprovação.

Tabela I - Quadro demonstrativo do número de alunos ao longo dos anos.

\begin{tabular}{|c|c|c|c|c|c|c|c|}
\hline Eng. Elétrica & 1987 & 1988 & 1989 & 1990 & 1991 & 1992 & 1993 \\
\hline $\begin{array}{c}\text { Relação Candidato } \\
\text { vaga - vestibular }\end{array}$ & 18,5 & 14,6 & 10,2 & 11 & 16,5 & 15,3 & 13,4 \\
\hline 10 ano & 40 & 40 & 40 & 40 & 40 & 40 & 40 \\
\hline 2o ano & - & 38 & 37 & 37 & 35 & 33 & 37 \\
\hline 3o ano & - & & 35 & 37 & 36 & 42 & 38 \\
\hline 4 ano & - & - & - & 30 & 26 & 30 & 37 \\
\hline 5o ano & - & - & - & - & 22 & 31 & 27 \\
\hline Formados & & & & & 20 & 21 & \\
\hline
\end{tabular}

\section{Corpo docente}

O Departamento de Eletricidade (DEL), responsável pelo oferecimento das disciplinas de formação profissional, possuía quinze professores. Esse departamento tinha por responsabilidade as disciplinas do curso de Engenharia Elétrica, do curso de Engenharia Mecânica (24 horas semanais) e do curso de Engenharia Civil (6 horas semanais). Dentro da estrutura do campus, o Departamento de Eletricidade era aquele que possuía o menor número de professores em relação ao número de disciplinas sob sua responsabilidade.

Entre os professores do DEL, cerca de $80 \%$ possuíam formação em Engenharia Elétrica. Apenas 47\%, aproximadamente, possuíam o título de doutor ou livre-docente. A maioria, cerca de $80 \%$, trabalhava em regime de dedicação exclusiva, porém, o restante era contratado por períodos de 12 ou 24 horas.
Devido ao reduzido número de docentes com titulação, poucas atividades de orientação estavam voltadas para projetos de Iniciação Científica. Dos quatorze alunos do curso envolvidos com trabalhos de Iniciação Científica, com bolsa da FAPESP ou CNPq, somente seis alunos eram orientados por professores do DEL. As demais orientações eram realizadas por professores do Departamento de Matemática e do Departamento de Física e Química. Assim, dos alunos que desenvolviam trabalhos de Iniciação Científica, um número em torno de $43 \%$ do total eram orientados por professores do DEL, esses correspondendo a somente $3,3 \%$ do total de alunos do curso de Engenharia Elétrica. A média de orientações era de 0,42 alunos por docente do DEL. A baixa relação entre alunos/professor pode ser creditada à elevada carga de outras atividades que os professores deviam cumprir dentro desse departamento, do 
campus de Guaratinguetá (atividades administrativas), bem como as relacionadas à obtenção do doutoramento.

Um número maior de docentes, especialmente com formação voltada para a engenharia elétrica e com uma maior titulação, refletiria diretamente na qualidade do curso.

\section{Infraestrutura}

A biblioteca da FEG possuía um acervo de 12.589 volumes, entre 7.000 títulos disponíveis; 1.029 revistas especializadas, recebendo em torno de 2.300 consultas mensais. Do acervo citado, a biblioteca possuía apenas 545 títulos de livros, 7,8\% do total, e 100 títulos de periódicos, aproximadamente $9,7 \%$ do total, voltados especificamente para o curso de Engenharia Elétrica. Ainda assim, 156 alunos, de um total de 179 matriculados no curso, possuíam cadastro e a utilizavam.

A área total construída era de, aproximadamente, $556 \mathrm{~m}^{2}$, com salas de estudos externas para 126 alunos, além de local reservado para reuniões. Esse espaço era compartilhado entre alunos da FEG (870 no total) e do Colégio Técnico Industrial (487 alunos). Assim, somente 9,2\% do total de alunos do campus tinham possibilidade de realizar seus estudos naquele local.

Parte dos laboratórios didáticos podia ser considerada de muito boa qualidade, e onde os docentes poderiam desenvolver uma eficiente metodologia de ensino, além de diversos trabalhos de Iniciação Científica. Os alunos podiam realizar individualmente seus experimentos, o que aumentava muito a eficiência do aprendizado. Porém, alguns dos laboratórios didáticos, principalmente os relacionados à área de eletrotécnica, apresentavam problemas e necessidade de melhorias.

\section{Avaliação do currículo vigente}

Uma análise do currículo em vigor em 1993, bem como das conclusões obtidas do processo de autoavaliação, realizado entre os anos de 1989 e 1992, mostrou que uma reestruturação curricular e uma nova proposta pedagógica seriam necessárias. As principais razões para isso foram:

- ausência de algumas disciplinas de formação profissional voltadas para os cursos de Engenharia Elétrica. A ausência dessas disciplinas era motivo de constantes reclamações por parte dos alunos, quando comparavam o currículo da FEG com o de outras universidades de conhecida excelência;

- ausência de disciplinas voltadas para a formação na interface eletrotécnica-eletrônica, proposta pedagógica do curso;

- ausência de elementos motivadores para a área de engenharia elétrica nas duas primeiras séries. $O$ aluno ingressante não tinha qualquer contato com disciplinas ou atividades que o contextualizasse dentro da profissão escolhida;

- formação profissional do aluno focada nas $3^{\mathrm{a}}$ e $4^{\mathrm{a}}$ séries do curso, fazendo com que o aluno tivesse de assimilar todo o conteúdo programático das disciplinas profissionalizantes em apenas dois anos. Esse curto espaço de tempo não permitia que os conhecimentos adquiridos fossem sedimentados e colocados em prática ainda durante o curso. Com isso, possíveis falhas de formação que ocorressem dificilmente seriam identificadas e corrigidas;

- ausência de articulação entre as disciplinas obrigatórias e optativas, não possibilitando ao aluno conseguir uma formação voltada para uma ênfase específica;

- má distribuição da carga horária e das disciplinas ao longo das séries, limitando o tempo de estudos e inviabilizando o desenvolvimento de atividades extraclasse, como trabalhos de Iniciação Científica e estágio.

A partir das constatações da análise realizada, concluiu-se pela existência de problemas no Projeto Pedagógico do curso, principalmente em relação à grade curricular, que não atendia às expectativas, sendo divergente dos objetivos propostos e necessitando de reformulação. 


\section{CONSTRUÇÃO DO PROJETO PEDAGÓGICO}

\section{Considerações iniciais}

A construção de um Projeto Pedagógico envolve diversas variáveis que poderão servir como obstáculos para se atingir o objetivo pretendido, caso não sejam adequadamente identificadas e trabalhadas. Algumas que, inicialmente, parecem ser de fundamental importância, mostram-se insignificantes frente ao tempo dedicado em sua adequação à proposta. Outras, desvalorizadas ao começo, devem ser reconsideradas devido à importância que alcançam. Identificar e ponderar essas variáveis são as principais dificuldades enfrentadas pelas pessoas envolvidas com o desenvolvimento do projeto.

Entre os pontos fundamentais a serem considerados, destacam-se a interação do curso com a comunidade externa, as condições proporcionadas pela instituição, o compromisso dela com o Projeto Pedagógico e, principalmente, a formação oferecida ao estudante.

Caso a necessidade seja iminente, devese considerar a possibilidade de alteração das propostas contidas em um Projeto Pedagógico durante sua implantação. Sendo a proposta construída por um grupo de pessoas, e em função da necessidade de mudança detectada, logo surgem divergências entre os membros, trazendo consigo desgaste e prejuízos ao curso. Visando a evitar essas consequências, ficou previamente estabelecido que todo e qualquer ajuste deveria ser meticulosamente analisado pelo Conselho de Curso, bem como os efeitos das alterações, antes de serem de aprovadas e implementadas.

\section{Projeto proposto e implantado na FEG/UNESP}

Antes do desenvolvimento do Projeto Pedagógico, foi essencial realizar um forte trabalho de convencimento junto à comunidade do campus sobre a necessidade das mudanças no projeto inicial do curso. Para isso, a identificação dos principais pontos que impediam que o curso alcançasse sua plenitude foi de suma importância. A partir do estudo realizado, estabeleceram-se premissas que serviram para balizar o processo de construção do novo Projeto Pedagógico, destacando-se os seguintes pontos:

- o curso possuía uma proposta adequada e voltada às necessidades da região em que se localizava;

- a grade curricular estava em desacordo com a proposta do curso;

- o departamento responsável pela formação profissional possuía um baixo número de docentes com titulação e formação para ministrar o curso pretendido;

- os laboratórios relacionados à área de eletrotécnica necessitavam urgentemente de melhorias;

- o campus possuía uma biblioteca com poucos livros e periódicos na área de engenharia elétrica, além de pouco espaço e precárias acomodações para uso de alunos e professores.

\section{Premissas balizadoras}

A construção do Projeto Pedagógico partiu de premissas que serviram para moldar e dar sustentação à nova proposta. Essas premissas foram:

\section{- Formação do aluno}

Estabeleceu-se que o perfil do profissional formado deveria ser mantido, conforme proposta original para o curso. No entanto, haveria a necessidade da adequação da grade curricular para contemplar os principais assuntos referentes às áreas de eletrotécnica $\mathrm{e}$ eletrônica, além de introduzir disciplinas pertinentes às suas interfaces, sem aumentar a carga horária total do curso.

\section{- Complemento de formação}

Estabeleceu-se que o curso proporcionasse ênfase aos interessados, desde que o aluno se dedicasse com maior afinco a uma área específica. Assim, os alunos receberiam "Certificados de Estudos Aprofundados", que deveriam estar previstos no projeto pedagógico e devidamente regulamentados pelos 
órgãos colegiados da instituição. Os alunos ansiavam e reivindicavam por isso.

\section{- Atividades curriculares}

Estabeleceu-se que, além das tradicionais aulas teóricas e práticas, diversas outras atividades deveriam ser previstas, de modo a abranger trabalhos bibliográficos, seminários, trabalhos e projetos técnicos, visitas técnicas, estágio supervisionado, trabalho de formatura, trabalhos de Iniciação Científica, participação e organização de eventos com atividades técnicas, culturais e esportivas.

Essa premissa foi definida em função do conhecimento exigido de um engenheiro no seu dia-a-dia, assim como das particularidades específicas dessa profissão, uma vez que o espectro de atividades exercidas é muito mais amplo do que se pode imaginar inicialmente. $\mathrm{O}$ exercício de liderança frente a outros funcionários, o isolamento, às vezes necessário, em busca de solução para um problema, a elaboração de relatórios, a apresentação de palestras, o contato com prováveis clientes e fornecedores, a participação em reuniões e, obviamente, a elaboração e/ou a execução de projetos são atividades comuns à rotina do engenheiro. $\mathrm{O}$ discernimento e preparo para desempenhar tão diversificadas tarefas deveriam ser adquiridos e desenvolvidos durante o período em que os alunos se encontrassem matriculados. $\mathrm{O}$ curso não poderia se restringir somente a fornecer a formação técnica da área, mas toda a educação e postura profissional necessárias para que os seus alunos viessem a exercer com toda segurança a sua profissão.

\section{- Metodologia de ensino}

Estabeleceu-se que a metodologia a ser empregada pelos professores que viriam a ministrar as disciplinas ficaria a critério de cada um, sem que nada fosse determinado no Projeto Pedagógico. Caberia a cada docente estabelecer a melhor forma de motivar e transferir os conhecimentos aos seus alunos. Contudo, o Conselho de Curso deveria ficar com o papel de avaliador dessa metodologia. Assim, o responsável pela disciplina deveria entregar ao Conselho, no início de cada período letivo, um plano de ensino no qual constaria a metodologia a ser utilizada, os objetivos a serem alcançados e as metas a serem atingidas. No final de cada período, o professor faria uma avaliação da disciplina ministrada, proporcionando um feedback para o Conselho e para si. Esse mecanismo possibilitaria subsídios para a preparação de aulas ao próximo docente que viesse a ministrar a mesma disciplina.

Apesar do Projeto Pedagógico não estabelecer a metodologia a ser adotada pelo docente, alguns balizamentos para os professores utilizarem quando do planejamento das disciplinas e preparação de suas aulas deveriam ser apresentados, observando-se os seguintes itens:

- incentivo à criatividade do aluno e introdução de novos enfoques na resolução de problemas que o capacitasse a resolver problemas reais, aliados ao domínio dos conhecimentos específicos;

- uso intensivo da informática nas mais diversas disciplinas, principalmente nas de caráter técnico, por meio de ferramentas computacionais (não se pode esquecer que esse projeto foi elaborado em 1993, quando o uso da informática não era tão intenso e difundido);

- citação de exemplos e exercícios aplicados e voltados para a engenharia elétrica, mesmo que a disciplina não fosse diretamente vinculada a essa área.

\section{- Avaliação do rendimento escolar}

Muitas são as variáveis que envolvem as características gerais da aprendizagem, e esse conceito encontra-se amplamente abordado na literatura, envolvendo uma longa discussão de ideias. O rendimento escolar do aluno nem sempre reflete de modo claro o grau de seu aprendizado. A avaliação do rendimento escolar está ligada a condições diversas e o controle desse processo se mostra extremamente complicado para ser realizado com eficácia pelos responsáveis. Assim, foi necessário encontrar mecanismos que possam ser 
usados para verificação e julgamento da aprendizagem do estudante.

Em função disso, se estabeleceu que o aluno viesse a ser avaliado pelo menos por dois mecanismos diferentes, na tentativa de se minimizar os problemas existentes. As provas e os testes estariam dentro do mesmo grupo nesse mecanismo. Seminários, projetos técnicos, trabalhos individuais ou em grupos, entre outros, seriam as formas alternativas de avaliação do aprendizado do aluno. Pressupôsse que, assim, seria possível avaliar o seu aprendizado de modo mais realista.

\section{Grade curricular proposta}

A grade curricular do curso de Engenharia Elétrica da FEG/UNESP foi um dos pontos identificados como problemáticos no diagnóstico realizado. Os principais motivos foram:

- ausência de disciplinas exigidas na formação profissional geral de um engenheiro eletricista;

- concentração das disciplinas de formação profissional nas $3^{\mathrm{a}}$ e $4^{\mathrm{a}}$ séries;

- ausência de disciplinas específicas dentro da ênfase que o curso se propunha a oferecer;

- ausência de disciplinas motivadoras nos primeiros anos;

- falta de articulação entre as disciplinas obrigatórias e optativas;

- má distribuição da carga horária ao longo do curso.

Com base nesses pontos, a grade curricular do novo projeto (Tabela II) foi elaborada, procurando corrigir os problemas identificados.

O novo Projeto Pedagógico seria implantado em um sistema seriado de matrícula, com periodicidade anual, seguindo as normas da UNESP, que possibilita a existência de disciplinas semestrais e anuais. As principais soluções introduzidas são apresentadas e discutidas a seguir.

- Introdução de disciplinas motivadoras no primeiro ano: para aumentar a motivação dos alunos ingressantes no curso, foram intro- duzidas duas disciplinas motivadoras. A primeira, denominada "Matemática Aplicada e Computacional", permitiria que o aluno tivesse contato com o microcomputador, desde o primeiro ano, pois esse se mostrou uma importante ferramenta no dia-a-dia do engenheiro, apesar de pouco difundida, no Brasil, em 1993. Na primeira parte do curso, o aluno aprenderia e faria uso de programas básicos, como: editores de texto, planilhas, compiladores, etc. $\mathrm{Na}$ segunda parte, aprenderia sobre modelagem matemática e utilização do computador para isso. A segunda disciplina denominou-se "Eletrônica Digital". Essa disciplina nos primeiros anos, além de motivadora, vinha ao encontro da necessidade de ampliar o tempo de contato do aluno com disciplinas técnicas.

- Formação básica em engenharia elétrica finalizando no terceiro ano: a grade curricular proposta introduziu diversas disciplinas técnicas no primeiro e no segundo ano do curso, que não necessitavam de base matemática. Desse modo, o aluno cursaria, no $1^{\circ}$ ano, a disciplina "Eletrônica Digital", no $2^{\circ}$ ano, cursaria as seguintes disciplinas: "Micro-processadores I", "Dispositivos Eletrônicos", "Eletrotécnica Geral e Materiais Elétricos". No $3^{\circ}$ ano, foram inseridas as disciplinas: "Transitório em Circuitos Elétricos", "Análise e Controle de Sistemas Dinâmicos", "Eletromagnetismo", "Circuitos Eletrônicos", "Microprocessadores II" e "Transformadores e Máquinas Elétricas". Desse modo, o aluno teria toda a sua formação técnica básica completada no final do $3^{\circ}$ ano. Assim, ele poderia escolher uma área específica para realizar as disciplinas optativas, de modo a aprofundar os seus conhecimentos e obter sua ênfase. As disciplinas de caráter aplicado teriam dois anos para serem cursadas.

- Introdução de disciplinas e tópicos específicos para contemplar a ênfase eletrotécnicaeletrônica: as seguintes disciplinas específicas foram introduzidas na grade curricular: "Interfaceamento Eletro-eletrônico", "Acionamentos Elétricos", "Eletrônica Industrial II" e "Engenharia de Software". Essas disciplinas não existiam na grade até então.

- Adequação de disciplinas à carga horária e aos objetivos do curso: novas disciplinas 
foram inseridas em substituição a outras, com carga horária e ementas mais adequadas aos objetivos do curso: "Eletromagnetismo", que passou de semestral a anual; "Instalações Elétricas Industriais", em substituição à "Instalações Elétricas I", passando de semestral a anual e com aulas de laboratório; "Instrumentação Industrial", com aulas práticas; "Controle Discreto", em substituição à "Controle Não Linear"; "Eletrônica Industrial I", em substituição à "Eletrônica de Potência e Técnicas de Pulso", "Análise e Controle de Sistemas Dinâmicos", em substituição às disciplinas "Análise de Sistema" e "Controle e Servomecanismo", que eram oferecidas separadamente.

- Desdobramento de disciplinas para adequação às necessidades do curso: as seguintes disciplinas foram desdobradas para melhor adequá-las à seriação do curso, passando a ser oferecidas separadamente: "Eletrotécnica Geral" e "Transitório em Circuitos", originadas da disciplina "Circuitos Elétricos"; "Dispositivos Eletrônicos" e "Circuitos Eletrônicos", a partir de "Eletrônica Básica"; "Microprocessadores I" e "Microprocessadores II", a partir de Sistemas Microprocessados.

- Introdução de disciplinas complementares à formação de engenharia: visando a fornecer uma formação diferenciada voltada às necessidades do mercado de trabalho, as seguintes disciplinas foram introduzidas em substituição a outras: "Tópicos em Engenharia da Qualidade" e "Legislação Trabalhista".
Analisados os efeitos dessa nova grade curricular, verificou-se que:

- $1^{\text {a }}$ série: o aluno inicia a sua formação em Engenharia com as disciplinas de formação básica (Matemática, Física e Química). Inicia, também, os seus estudos em disciplinas de caráter profissional (Eletrônica Digital e Laboratório de Eletrônica Digital). Por meio de disciplinas de caráter motivador (Matemática Aplicada e Computacional, e Eletrônica Digital), procurou-se diminuir a evasão verificada no primeiro ano. $\mathrm{O}$ início de disciplinas de caráter profissional nessa série viabiliza que toda formação profissional geral seja alcançada no final da terceira série.

- $2^{\mathrm{a}}$ série: um maior número de disciplinas técnicas é introduzido. Além de continuar o seu aprendizado na área da Eletrônica Digital, o aluno inicia os seus estudos das áreas de Eletrotécnica e Eletrônica Analógica. Também é dada continuidade às disciplinas de formação básica e geral.

- $3^{\mathrm{a}}$ série: nessa série, o aluno completa toda a sua formação profissional geral, estando preparado para iniciar os estudos das disciplinas de caráter aplicado.

- $4^{\mathrm{a}}$ série: inicia-se a formação mais especializada do aluno, através das disciplinas optativas, bem como as disciplinas de caráter aplicado ("Análise de Sistemas de Potência", "Eletrônica Industrial", etc.).

- $5^{\text {a }}$ série: ocorre a finalização da formação do aluno por meio de disciplinas previstas para essa série, realização do estágio curricular e a execução de um Trabalho de Conclusão de Curso. 
Tabela II - Distribuição das disciplinas ao longo das séries.

\begin{tabular}{||l|l|c|c|c|c|}
\hline \multicolumn{1}{|c|}{ Disciplina } & \multicolumn{3}{c|}{ Carga horária } & \multicolumn{2}{c|}{ Créditos } \\
\hline \hline \multirow{6}{*}{ SÉRIE } & - Cálculo Diferencial e Integral I & $4-0$ & $4-0$ & 120 & 8 \\
& - Álgebra Linear e Cálculo Vetorial & $3-0$ & $3-0$ & 90 & 6 \\
& - Matemática Aplicada e Computacional & $1-1$ & $1-1$ & 60 & 4 \\
& - Física Geral I & $4-0$ & $4-0$ & 120 & 8 \\
& - Física Experimental I & $0-2$ & $0-2$ & 60 & 4 \\
$1^{\mathbf{a}}$ & - Química Geral e Tecnológica & $3-0$ & $3-0$ & 90 & 6 \\
& - Química Experimental & $0-2$ & $0-2$ & 60 & 4 \\
& - Desenho Técnico Básico & $0-2$ & $0-2$ & 60 & 4 \\
& - Eletrônica Digital & $3-0$ & $3-0$ & 90 & 6 \\
& - Laboratório de Eletrônica Digital & $0-2$ & $0-2$ & 60 & 4 \\
& - Educação Física & $0-2$ & - & 30 & 2 \\
\cline { 2 - 6 } & Total 1a série & $\mathbf{1 8 - 1 1}$ & $\mathbf{1 8 - 9}$ & $\mathbf{8 4 0}$ & $\mathbf{5 6}$ \\
\hline
\end{tabular}

\begin{tabular}{|c|c|c|c|c|c|}
\hline \multirow{2}{*}{ SÉRIE } & \multirow{2}{*}{ Disciplina } & \multicolumn{3}{|c|}{ Carga horária } & \multirow{2}{*}{ Créditos } \\
\hline & & $1^{\circ} \mathrm{Sem}$. & $2^{\circ}$ Sem. & $(T+P)$ & \\
\hline \multirow{14}{*}{$2^{a}$} & - Cálculo Diferencial e Integral II & $4-0$ & $4-0$ & 120 & 8 \\
\hline & - Computação e Cálculo Numérico & 3-1 & $3-1$ & 120 & 8 \\
\hline & - Física Geral II & 4-0 & $4-0$ & 120 & 8 \\
\hline & - Física Experimental II & $0-2$ & $0-2$ & 60 & 4 \\
\hline & - Eletrotécnica Geral & $4-0$ & $4-0$ & 120 & 8 \\
\hline & - Laboratório de Eletrotécnica & $0-1$ & $0-1$ & 30 & 2 \\
\hline & - Microprocessadores & $3-0$ & $3-0$ & 90 & 6 \\
\hline & - Laboratório de Microprocessadores & $0-2$ & $0-2$ & 60 & 4 \\
\hline & - Estática e Introdução à Resistência dos & & & & \\
\hline & Materiais & 3-0 & $3-0$ & 90 & 6 \\
\hline & - Materiais Elétricos & $2-1$ & $4-0$ & 45 & 3 \\
\hline & - Dispositivos Eletrônicos & - & $0-2$ & 60 & 4 \\
\hline & - Laboratório de Dispositivos Eletrônicos & - & & 30 & 2 \\
\hline & Total $2^{\mathrm{a}}$ série & $23-7$ & $25-8$ & 945 & 63 \\
\hline
\end{tabular}

\begin{tabular}{|c|c|c|c|c|c|}
\hline \multirow{2}{*}{ SÉRIE } & \multirow{2}{*}{ Disciplina } & \multicolumn{3}{|c|}{ Carga horária } & \multirow{2}{*}{ Créditos } \\
\hline & & $1^{\circ} \mathrm{Sem}$. & $2^{\circ} \mathrm{Sem}$. & ( $(T+P)$ & \\
\hline \multirow{13}{*}{$3^{\mathbf{a}}$} & - Circuitos Eletrônicos & 4-0 & 4-0 & 120 & 8 \\
\hline & - Laboratório de Circuitos Eletrônicos & $0-2$ & $0-2$ & 60 & 4 \\
\hline & - Análise e Controle de Sistemas Dinâmicos & $4-0$ & $4-0$ & 120 & 8 \\
\hline & Sistemas Dinâmicos & $0-1$ & $0-1$ & 30 & 2 \\
\hline & - Eletromagnetismo & 3-1 & 3-1 & 120 & 8 \\
\hline & - Transformadores e Máquinas Elétricas & $4-0$ & $4-0$ & 120 & 8 \\
\hline & Elétricas & $0-1$ & $0-1$ & 30 & 2 \\
\hline & - Probabilidade e Estatística & $2-0$ & $2-0$ & 60 & 4 \\
\hline & - Transitório em Circuitos Elétricos & $3-0$ & - & 45 & 3 \\
\hline & - Sistemas Microcomputadorizados & $2-1$ & - & 45 & 3 \\
\hline & - Fenômeno de Transporte & - & 3-1 & 60 & 4 \\
\hline & - Engenharia de software & - & $2-1$ & 45 & 3 \\
\hline & Total da $3^{\mathrm{a}}$ série & 22-6 & $22-7$ & 855 & 57 \\
\hline
\end{tabular}




\begin{tabular}{|c|c|c|c|c|c|}
\hline \multirow{2}{*}{ SÉRIE } & \multirow{2}{*}{ Disciplina } & \multicolumn{3}{|c|}{ Carga horária } & \multirow{2}{*}{ Créditos } \\
\hline & & $1^{\circ}$ Sem. & $2^{\circ}$ Sem. & $(T+P)$ & \\
\hline \multirow{13}{*}{$4^{a}$} & - Princípio de Comunicações & 3-1 & 3-1 & 120 & 8 \\
\hline & - Eletrônica Industrial I & $3-0$ & $3-0$ & 90 & 6 \\
\hline & - Laboratório de Eletrônica Industrial I & $0-2$ & $0-2$ & 60 & 4 \\
\hline & - Análise de Sistemas de Potência & $4-0$ & $4-0$ & 120 & 8 \\
\hline & - Instalações Elétricas Industriais & $3-1$ & $3-1$ & 120 & 8 \\
\hline & - Economia de Empresa & $2-0$ & $2-0$ & 60 & 4 \\
\hline & - Psicologia Aplicada ao Trabalho & $2-0$ & - & 30 & 2 \\
\hline & - Controle Discreto & $3-1$ & - & 60 & 4 \\
\hline & - Optativa I & $3-0$ & & 45 & 3 \\
\hline & - Acionamentos Elétricos & - & $3-1$ & 60 & 4 \\
\hline & - Tópicos em Engenharia da Qualidade & - & $2-0$ & 30 & 2 \\
\hline & - Optativa II & - & $3-0$ & 45 & 3 \\
\hline & Total da $4^{\mathrm{a}}$ série & $23-5$ & $23-5$ & 840 & 56 \\
\hline
\end{tabular}

\begin{tabular}{|c|c|c|c|c|c|}
\hline \multirow[t]{2}{*}{ SÉRIE } & \multirow{2}{*}{ Disciplina } & \multicolumn{3}{|c|}{ Carga horária } & \multirow{2}{*}{ Créditos } \\
\hline & & $1^{\circ}$ Sem. & $2^{\circ}$ Sem. & $(\mathrm{T}+\mathrm{P})$ & \\
\hline \multirow{10}{*}{$5^{a}$} & - Geração, Transmissão e Distribuição de & 3-0 & $3-0$ & 9 & 6 \\
\hline & - Interfaceamento e controle Eletro-Eletrônico & $3-1$ & 3-1 & 120 & 8 \\
\hline & - Organização da Produção & $2-0$ & $2-0$ & 60 & 4 \\
\hline & - Eletrônica Industrial II & $3-2$ & - & 75 & 5 \\
\hline & - Ciências do Ambiente & $2-0$ & - & 30 & 2 \\
\hline & - Optativa III & $3-0$ & - & 45 & 3 \\
\hline & - Instrumentação Industrial & - & $3-2$ & 75 & 5 \\
\hline & - Direito & - & $2-0$ & 30 & 2 \\
\hline & - Planejamento e Controle da Produção & - & $2-0$ & 30 & 2 \\
\hline & Total da $5^{\mathrm{a}}$ série & 16-3 & $15-3$ & 555 & 37 \\
\hline
\end{tabular}

\section{IMPLANTAÇÃO DO PROJETO}

\section{Sistemática adotada}

A metodologia adotada para a implantação do novo Projeto Pedagógico pode ser dividida em duas frentes: a primeira consistiu em sanar os problemas identificados quando da realização da avaliação do cenário preexistente, relacionados, basicamente, com as falhas na infraestrutura da instituição e em seu quadro de professores; a segunda correspondeu à implantação das modificações de caráter pedagógico e curricular do curso. As duas frentes ocorreram de modo simultâneo.

A partir do novo Projeto Pedagógico, foi implantado o regime seriado de matrícula, diferentemente do sistema por créditos, adotado até então. A nova sistemática previu que sua implantação seria iniciada em 1995, para a primeira série do curso de Engenharia Elétrica. Em 1996, seria implantado para a primeira e segunda séries, e assim sucessivamente, de modo que, no final de 1999, a turma ingressante em 1995 fosse a primeira turma a se graduar inteiramente baseada no novo Projeto Pedagógico. Por esse motivo, a partir do ano de 1995, não foram mais oferecidas disciplinas da antiga grade para a primeira série. Os alunos que ingressaram em 1994, no sistema de matrícula por créditos, e tiveram reprovação em disciplinas que não mais seriam oferecidas, obtiveram os créditos equivalentes cursando outras disciplinas, predefinidas dentro de um quadro de equivalência previamente elaborado e aprovado pelos órgãos colegiados. Para a elaboração desse quadro, 
foram considerados os casos abaixo relacionados:

- disciplinas com mesmo número de créditos e ementa, inclusive as que estivessem com nomes distintos em suas respectivas grades, teriam os créditos convalidados diretamente;

- disciplina do currículo novo com número de créditos maior do que a disciplina equivalente do currículo antigo exigiria atividade extra por parte do aluno quando a cursasse, de modo a integralizar os créditos exigidos. Essa atividade poderia ser proposta pelo professor da disciplina e aprovada pelo Conselho de Curso ou, ainda, definida diretamente pelo Conselho de Curso da Engenharia Elétrica;

- disciplina do currículo novo com número de créditos menor em relação à do currículo antigo não necessitaria de qualquer complementação;

- os casos omissos seriam discutidos pelo Conselho de Curso da Engenharia Elétrica e deliberados pela Congregação da FEG.

\section{RESULTADOS ALCANÇADOS}

A avaliação externa é a melhor forma de avaliar uma nova proposta pedagógica. No caso apresentado, a proposta foi avaliada através da participação dos alunos submetidos ao antigo Exame Nacional de Cursos, o Provão. Desde a primeira vez em que os alunos foram submetidos a essa avaliação, quando estavam no quinto ano do curso, em 1999, até 2003, última vez em que o Provão foi aplicado, o curso obteve sempre o conceito "A". Logo na primeira participação dos alunos submetidos a esse novo Projeto Pedagógico ocorreu um aumento em $12,5 \%$ na média obtida, levando o curso do conceito "B" para o "A" (INEP, 2000). No ano de 2001, o curso de Engenharia Elétrica da FEG/UNESP foi classificado entre os três melhores do estado de São Paulo, à frente de instituições que, tradicionalmente, ocupavam esse espaço, como o curso da Unicamp, da USP de São Carlos e Federal de São Carlos (INEP, 2002).

\section{CONCLUSÕES}

A implantação do Projeto Pedagógico exigiu um grande esforço de todos os envolvidos. A instituição procurou sanar os problemas identificados, permitindo que a implantação ocorresse sem grandes dificuldades. No ano de 1999, quando a turma de 1995 se graduou, o Departamento de Engenharia Elétrica - DEE, antigo Departamento de Eletricidade - DEL, tinha aumentado em $20 \%$ o seu quadro docente e crescido em $71 \%$ o número de professores com titulação de doutor ou livre-docente. O número de professores com dedicação exclusiva aumentou em cerca de $15 \%$, bem como aqueles com formação em Engenharia Elétrica, que passou para $33 \%$. Todos esses fatos refletiram no crescimento de $184 \%$ no número de alunos de Iniciação Científica orientados por professores do DEE, com bolsa da FAPESP ou do CNPq.

Uma nova biblioteca, com mais de 1.000 $\mathrm{m}^{2}$ de área foi inaugurada em 1999. O número de livros passou de 12.589 para 14.955 no ano de 2000 , um crescimento de cerca de $19 \%$, e continuou a crescer, chegando em 2010 a 26.800 volumes. Investimentos na ordem de 1,5 milhões de reais foram realizados nos laboratórios didáticos do Departamento de Engenharia Elétrica, a partir de 2001.

Em relação à nova proposta pedagógica, elaborada a partir dos processos de autoavaliação, pode-se constatar que as mudanças de paradigmas, como a introdução de disciplinas motivadoras nos primeiros anos do curso, a abertura de um maior tempo para o oferecimento das disciplinas técnicas no primeiro ano, a conclusão das disciplinas de caráter profissional geral no final do terceiro ano, entre muitas outras apresentadas neste trabalho, se mostraram adequadas e levaram o curso a alcançar outro patamar de qualidade. Porém, deve-se ressaltar o papel do projeto pedagógico dentro do departamento e da instituição. Ele serviu de elemento motivador, norteador e agregador, centralizando em torno da sua implementação as discussões e decisões que colocaram o curso de Engenharia Elétrica da FEG/UNESP junto aos mais bem conceituados do gênero no país. 


\section{REFERÊNCIAS}

BITTENCOURT, R. M., AZEVEDO,T.C. Projeto pedagógico: uma incógnita para os cursos de engenharia. Revista de Ensino de Engenharia. Brasília, DF, v. 23, p. 25-33, 2004.

BOTURA JUNIOR, G., LUCENA, S., AZEVEDO, T. A. N., MOTA, R. P., Projeto Pedagógico para implantação do Curso de Graduação em Engenharia de Controle e Automação no Campus de Sorocaba. Pró-reitoria de Graduação da UNESP - novembro de 2002.

BOTURA JUNIOR, G.; MARQUES, M. A.; LEMOS, M. A.; ROSA, L. C. Apresentação do processo de elaboração do Projeto Pedagógico de um curso de Engenharia avaliado com conceito "A" cinco vezes consecutivas no "Provão" - MEC. 8vo Congreso Internacional de Educatión Superior, 2012, Havana, 2012.

BOTURA JUNIOR, G.; ZANI, A. C.; VICENTE, $O$. Presentation and discussion about the curriculum for Electric Engineering at the Londrina State University - UEL. International Conference on Engineering and Computer Education, 2000, São Paulo, 2000.

INEP - Instituto Nacional de Pesquisas Educacionais, Relatório Síntese, Brasília, DF, 2000.

INEP - Instituto Nacional de Pesquisas Educacionais, Relatório Síntese, Brasília, DF, 2002.

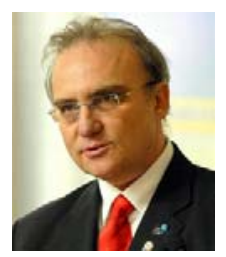

\section{DADOS DOS AUTORES}

Galdenoro Botura Jr. - Engenheiro pelo Instituto Nacional de Telecomunicações - INATEL, 1980, Doutor em Engenharia Elétrica pela UNICAMP, 1991, Livre-Docente pela UNESP, 1997. Coordenador do curso de Engenharia Elétrica do Campus de Guaratinguetá/UNESP - 1989 a 1992, 1993 a 1996, e 1998. Coordenador da Área de Engenharia, Arquitetura e Desenho Industrial da UNESP 2001 a 2005, Coordenador Executivo e responsável pela implantação do Campus de Sorocaba/UNESP - 2003 a 2009. Encontra-se atuando no Campus de Sorocaba/UNESP, no curso de Engenharia de Controle e Automação. Em ensino, possui interesse na área de estruturas curriculares, metodologias de ensino e gestão voltada à aprendizagem.

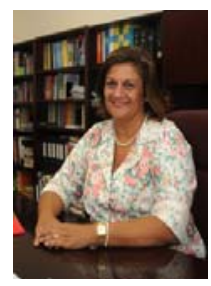

Tania Cristina Arantes Macedo de Azevedo - Bacharel em Física pelo Instituto de Física da Universidade de São Paulo - IFUSP, 1979, Doutora em Física pela IFUSP, 1989. Diretora da Faculdade de Engenharia do Campus de Guaratinguetá/UNESP - 2000 a 2004. Superintendente Acadêmico da Fundação VUNESP desde 2009. Em ensino, pesquisa a área relacionada com avaliação educacional.

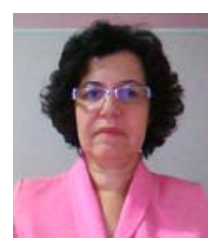

Marilza Antunes de Lemos - Engenheira Eletricista pela Faculdade de Engenharia de Sorocaba 1983, Doutora em Engenharia Elétrica pela Escola Politécnica da USP, 2004. Professora Assistente Doutora pela UNESP desde 2005. Coordenadora do curso de Engenharia de Controle e Automação pela UNESP Sorocaba - 2008 a 2010. Temas de interesse atuais no campo da educação em engenharia são: robótica educacional, sistemas tutores inteligentes e padrões para ensino de programação. Outros interesses envolvem robótica móvel, sistemas embarcados e modelagem de sistemas baseados em conhecimento.

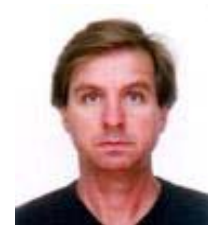

Márcio Alexandre Marques - Bacharel em Física pelo Instituto de Física e Química - USP/São Carlos, 1989. Doutor em Física pela USP/São Carlos, 1998. Professor Assistente Doutor pela UNESP desde 2003. Coordenador do curso de graduação em Engenharia de Controle e Automação da UNESP Sorocaba - 2005 a 2008. Em ensino, possui interesse na área de métodos de ensino e educação voltada à terceira idade.

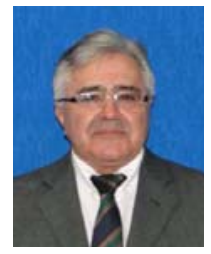

Luiz Carlos Rosa - Engenheiro Mecânico pela Universidade Estadual de Campinas - UNICAMP 1975, Doutor pela POLI/USP - 2004. Vice-Diretor da Faculdade de Tecnologia de Sorocaba FATEC/Sorocaba - desde 2008. Professor Assistente Doutor na UNESP/Sorocaba desde 2004. Professor da FATEC/Sorocaba desde 1980. Em ensino possui interesse na área de gestão do ensino de engenharia. 